Dutch Journal of Finance and Management
2019, 3(1), em0056
ISSN: $2542-4750$

\title{
Investigate the Business Intelligence Development and Improvement
}

\author{
Mohammad Ismail Rostaminiya ${ }^{1}$, Arash Hossin Zadeh Fard ${ }^{2 *}$ \\ ${ }^{1}$ Professor Associate and Head of Department of Islamic Management of Emam Sadegh University, IRAN \\ ${ }^{2}$ Master of Public Administration, Financial Tendency, Payam Noor University, Tehran, IRAN \\ *Corresponding Author: arashhossinzadeh@gmail.com \\ Citation: Rostaminiya, M. I. and Zadeh Fard, A. H. (2019). Investigate the Business Intelligence \\ Development and Improvement. Dutch Journal of Finance and Management, 3(1), em0056. \\ https:// doi.org/10.29333/djfm/5873
}

Published: April 22, 2019

\begin{abstract}
The purpose of this project is to investigate the business intelligence development and improvement in order to implement in monetary system. This research is functional in term of objective, and Descriptive survey in term of gathering information. According to the previous studies, 4 aspects and 19 indicators were identified for the development and improvement of BI. Identified aspects include management, human, financial and technical aspects. A questionnaire was developed on the basis of the model and its validity was confirmed. Data analysis shows that the performance of business intelligence system in financial and monetary system is in good condition. Management, human, technical and financial aspects are considered as strong to weak aspect of performance of the business intelligence system in the organization. At the end of the study, also measures to improve the business intelligence system to enhance the performance of this system were introduced in the organization.
\end{abstract}

Keywords: business intelligence, business intelligence tools, information technology, dimensions and effective measures

\section{INTRODUCTION}

On the other hand, massive improvements in all areas of information technology, has led to today's managers deal with a wealth of valuable information and unavoidably that this information should be cleared and processed as organization management systems data. This processed information, eventually become reliable "knowledge" that are effective role in decision-making and managers' decision-making (Amini, 2009). Analysts believe that the competitive advantage of an organization depends on two factors: quick access to adequate and reliable information and high selectivity in the establishment and exploration of the information. Hence, the search for effective means to create, collect, and share knowledge in an organization has become a key target of management. Among the one of the main concepts and affluence of management systems in the world today, the concept of business intelligence is as a decision support system. Business intelligence systems, through the collection, organization, analysis and sharing of important information related to the business, give insight to managers and other users, the insight that help to make a better business decisions in less time. These systems through the optimize use of stored data in the databases of the organization try to change information to awareness and intelligence. As it clears from the introduction, requirement to business intelligence solutions already in organizations and businesses to survive in the competitive market become sensitive to achieve a competitive advantage in today's volatile and strongly. In this study, we consider the development and measure indicators of business intelligence to implement monetary and financial system and we will identify the effective dimensions and indicators to implement. 
Today's business environment in which organizations are active, more and more advanced variable every day, and organizations, regardless of being public or private, incur increased pressure that forces them to response the changing condition and act in a more creative way. For many years, management information systems, organizations are supported in their various tasks, but today, management information systems, such as: (Decision support systems, expert systems, senior managers' information systems) have failed to meet the expectations of corporate decision makers, particularly in the following circumstances: Taking decisions in urgent time, block the competition, get different information with different opinions, constantly analyzes the data and see many different variables related to organizational performance. In financial organizations like banks and etc. due to the large size of the organization and development of their business, monitoring and inspecting of the huge volume of activities is really difficult. In every business, there are always people who disobeyed and disobeying the rules and regulations for their own interests that it would cause to financial loss and damage the reputation of the organization. Banks, like other public and private organizations to deal with offenses, have a special department called the Department of Inspection and Supervision. This department according to specific rules and regulations, monitor, control and inspect the activities that take place in the bank. Although, this department train and employ many people to do this difficult job but facing with a shortage of force. On the one hand, they are faced with a problem such as using energy efficiency; it is really difficult because of the large number of customers, transaction volume and variety of financial services offered by banks. On the other hand, they apply information systems that they are not effectively helps them. In addition, due to the large volume of data and information, surveillance and inspection in all cases are not possible for them (Hosseini, 2004). With regard to other issues, technologies such as business intelligence to facilitate the work of inspection and supervision are recommended. Use of business intelligence technologies will give surveillance capabilities and focus to them that it will have affective results; so the most important question that arises in this study is which indexes of business intelligence to implement in the monetary and financial system?

In the competitive world of today's dynamic environment, the data collecting, process and analyzing is essential to understand how to operate the business, predicting outcomes and improve the effectiveness of business processes.

Implementation of business intelligence solutions in the organization will be very costly. These costs are summarized as follows:

\section{Financial Costs}

The cost of upgrade or purchase hardware equipment

The cost of purchasing related software

The cost of consulting services

The cost of IT personnel training

The cost of training managers in order to use the system

The human cost: Requires at least 2 information system experts for implementation

The time cost: Implementation time of business intelligence is between 6 months to several years.

Now, according to the cost that an organization must pay to implement this strategy, at first it needs to extract and evaluate all indexes of the business intelligence. Another reason that reveals the necessity of this research is being new and fresh implementation of this approach among organizations and local companies, and because there is no complete experience in this field, increases the risk of the project, and this research will help to reduce implementation risk.

\section{Research Purposes}

The main aim of this study was to identify the status of business intelligence in financial and monetary system in order to achieve the following objectives will be pursued.

- Recognition of the relationship between the technical and business intelligence, manufacturing in and financial and monetary system

- Understanding the relationship of management and business intelligence in monetary and financial system

- Understanding the relationship between the human aspect and financial business intelligence system

- Understanding the relationship between financial aspect and business intelligence in financial and monetary system

\section{Review of Literature}

The definition of business intelligence: Business intelligence with respect to the use of the intelligence word has two basic definitions. The first definition is related to the human intelligence activities and organizational matters that be used less. Business intelligence is a new field of research on potential application of human intelligence and artificial intelligence technologies, decision support systems of intelligent management for the organization's various issues. The second definition recounts intelligence as valuable information for publication 
and communication that includes the use of expert information, knowledge and effective technology in the management of the organization. So business intelligence is called to a broad group of applications and technologies that help users to collect the data, access to data and analysis for better decision-making in the organization. This term refers to that you should have comprehensive knowledge of all the factors that impact on your organization. Ayrinee and Homokiyano considered business intelligence systems as a means of exploiting information to help managers to solve the structured and non-structured problems. Each aspects of the business intelligence systems can be used for the management of information activities too (a) to obtain information (b) storing and searching for information (c) information analysis (d) provide the information. Rasmussen believes that organizations need effective tools of business intelligence for better decision making. He states that the organizations spend a lot of time to prepare data and financial reports from the past, and spend little time to analyze the data.

\section{History of Business Intelligence}

For the first time, business Intelligence was introduced in 1958 by Hans-Peter Lohen. Years later, in 1989, Howard Dresdner, a researcher at Gartner Group generalize "BI" as a term used to describe a set of concepts and methods to improve decision-making of organization by using computer support systems. In fact, the roots of BI return to reporting systems of management information systems (MIS). At that time, reporting systems are fixed and have not adequate capabilities. In the early 80 s, the concept of executive information systems (EIS) emerged that is to support senior management activities of organizations. Some of the features include multi-dimensional reporting systems, process analysis, to analyze critical success factors (CSF).

The structure of the business intelligence system: A business intelligence system is composed of four levels and a Metadata. The various aspects of business intelligence systems work together to facilitate basic tasks:

Extracted data is from operational systems, storage of extracted data in a data base and retrieval of stored data for different analytical applications of the organization.

Level of operating systems: The level of operational systems in organization are primarily online transaction processing systems (OLTP), which supports the organization's daily operations. OLTP systems include some customer requests processing systems, financial systems, human resource management systems and etc.

The level to obtain data: This level consists of three steps: extraction, transformation, loading. Organizations have different OLTP systems that are usually produce large amounts of data. At first, this data from OLTP systems extracted by ETL process and then accordance with a set of conversion rules, some changes and transforms being carried out in them, in fact, the raw data turn into a form that can be analyzed, finally, after clearing and the integrity of the data be loaded in the data base. ETL is the most essential component of a BI system because ETL process relies primarily on the quality of all other aspects.

Level of data storage: The data are loaded from organization's OLTP systems into database and based on predefined models. Star and snowflake design are the most popular, database projects. No matter what type of projects designed on a database.

The analytical level: Based on databases, various types of analytics software have been developed. Business intelligence system supports two basic types of analytical functions: reporting and online analytical processing (OLAP). Reporting duty is to provide reports to managers across the organization. Reports were created by implementing database queries that have already been defined by its designers, so the reports generated by business intelligence have fixed form and include a variety of stable data. Most Business Intelligence analysis are OLAP, these tools enable managers to create an effective organization of data from different analytical dimensions. Compared with the task of reporting, OLAP supports analysis are not pre-defined business managers by selecting different analytical dimensions, full control over their data. Other types of analytic applications, including data mining, management dashboards, performance management of organization and etc., which are also use to classify and analyze data, and results present in the form of detailed reports and multipurpose.

The analytical tools of organization: Many organizations have collected large volumes of data and this large volume can be discovered valuable communication that leads organizations to success. The analytical tools of organization are including online analytical processing (OLAP), data mining, data visualization technologies and advanced analytical techniques. Input data, in order to analysis, can be found in the database, operational database, web services and files were scattered in the organization. In fact, business intelligence includes a set of tools to collect, integrate, analyze and display large volumes of information for better decision making. By using analytics software of organizations, the user can query on the data, created pre-defined reports and observed the result in the form of reports, notices and other graphical displays.

\section{Online Analytical Processing (OLAP)}

In 1993, by E. F, code was introduced as a tool that can provide dynamic analysis of the data (Lux et al., 1387: 109). OLAP is used for reporting, analysis, modeling and planning to optimize business. OLAP provides 
summarized reviews, multidimensional business data and create this facility for managers who received business data from various analytical dimensions effectively. Online analytical processing helps organizations to detect weaknesses, threats, opportunities and chances.

A variety of online analytical processing (OLAP)

1- Dimensional OLAP

2- Connectional OLAP

3- Integrative OLAP

The reasons of organizations' need to business intelligence: In a broad view, organizations need to use business intelligence for three main objectives; first in order to analyze which can help them to make better decisions. Second it will help to achieve the fundamental objectives of the organization, such as lower costs, improve productivity, develop customer service, increase revenue, and etc. Third, provide strategic information for decision makers.

Some other reasons are including:

- Organizations are changing.

- Decisions making are constantly occurring in all levels of the organization.

- All data may not be compatible with each other.

- Obtain data or reports usually require a plan to represent report.

- More data stored on systems that lead to users' difficult access to them.

- Database is designed to transactions processing, not for pre-defined reporting.

- It is possible that there are no enough copies of saving data for reporting the status of operating systems.

- A better understanding of customer.

The process of business intelligence in organizations: The process of business intelligence in organizations is a dynamic and interactive process. This process starts with a question and answers of the questions are provided in a repetitive loop. These answers provide decision possibility. These processes are following:

1. Planning and guidance

2. Stages of the obtain information from the database

3. Information processing

4. Analyzing and production of information

What is the business intelligence usage at the different levels of organization? (Strategic importance of business intelligence in organization's decisions).

\section{Business Intelligence function can be Divided into Three Areas}

1. The strategic levels: related to the macro-organization decisions that are made by high-level managers. These kinds of usage performed in low frequency and long periods, but it may be associated with high volumes of data and processing. Decisions made at this level often non-structured issue and by senior management, the results of the decisions have long-term and major impact on the organization (Park, 2007: 14). At the strategic level, business intelligence systems became possible the precise adjustment of their goals and provide follow-up to achieve.

2. Tactical level: related to the operation is performed in the area of middle managers. These operations may include follow-up actions at a low level, how to do it, finally concluding reports and useful data for decision-making of the organization's medium-term. Decisions made at this level by middle managers are often semi-structured issues. At the tactical level, business intelligence systems may be created the basis for decision-making in line with market management, financial management, and asset management.

3. The operational level: it is the lowest level of activities in an organization that usually operating within the ranks of the organization at times repetitive and dealing with a small amount of data. Decisions made at this level often structured issues and made by lower-level managers. The results of the decisions have short-term and split effects on the organization. At the operational level, business intelligence systems for the case analysis and answer to questions relating to continuing operations departments used updated financial estimates, cooperation with customers and etc. Hack nee states that the main idea of business intelligence is the recognition of the information needs, data processing and turn them into valuable management information and knowledge. Information needs are different at different levels of decision. In fact, the strategic decision makers need to foreign, broad, integrated and future information for future operations of organization. While at the operational level, most internal, detailed, specific information is required to do daily activities. Business Intelligence plays an important role in providing this information at different levels of the organization for timely and well decisions. In fact, business intelligence was understood as a systematic process that the organization published collect and store the required information from internal and external sources to implement the activities and decisions making. 


\section{The impact of business intelligence on the organizations}

Amini (2009) are categorized the effect of using business intelligence in organizations as follows:

\section{A) Direct effects}

1. From a management perspective: acceleration, optimization and enhance the level of quality in decisionmaking processes and decision-making, better and more realistic forecasts of future changes and lack of surprise, to achieve real and usable reports by removing incorrect and insufficient information and incorrect statistics, etc. that finally, all of this leads to lower costs and increase revenues of organization.

2. The perspective of architecture and processes of the organization: to provide a bedridden to move from data to information and information to business first-hand information and create add value to the organization and increase organizational efficiency, reduce additional processes, integration and unity of organization's processes.

3. From the perspective of market and competition: improve and create competitive advantage by using powerful tools to analysis market and competitors, to smart monitor of business customers and partners, better serve to customers and communicate with them effectively, intelligent monitoring of the market and identify its future changes.

4. From the perspective of technology: the creation of a technical platform and architecture for the development and use of resources, provide interaction with other software systems such as customer relationship systems, integrated systems and increase the efficiency of their organization.

\section{B) Indirect effects}

1. Full support of knowledge management: a strategy of business intelligence can be support knowledge management fully, on time and at the right time in terms of data and information. It means business intelligence can play a role as the feeder of data and to produce knowledge and information.

2. The improvement factors of organizational knowledge: in fact, the beginning of the formation of knowledge is data. Knowledge management systems need to clean data, without conflict, classified and summarized that business intelligence provides it by extracting, transforming and cleansing data in a database.

\section{Conceptual Model}

- Trend in investment management and use of BI solutions

- Support for the management of BI solutions

- Trading in layer management software solutions and the ability to use a computer and software

- Type of decision (realistic or emotional) in

- Number of users of information systems organization

- Partnership staff

- Workforce training

- welcoming new ideas

- Responsibilities ready

- The ability to use knowledge-based reports and information systems in decision-making in the organization

- Human Resources resistance to change

- The public confidence in the output of the software and use it for decision-making in the

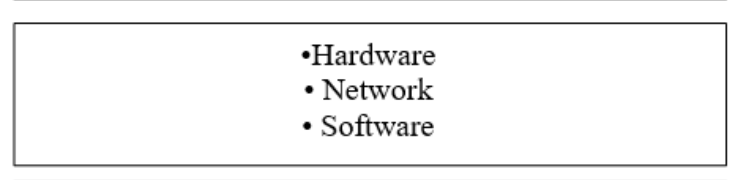

- Cost - Benefit

- Supply (budget)

- Usability of capital

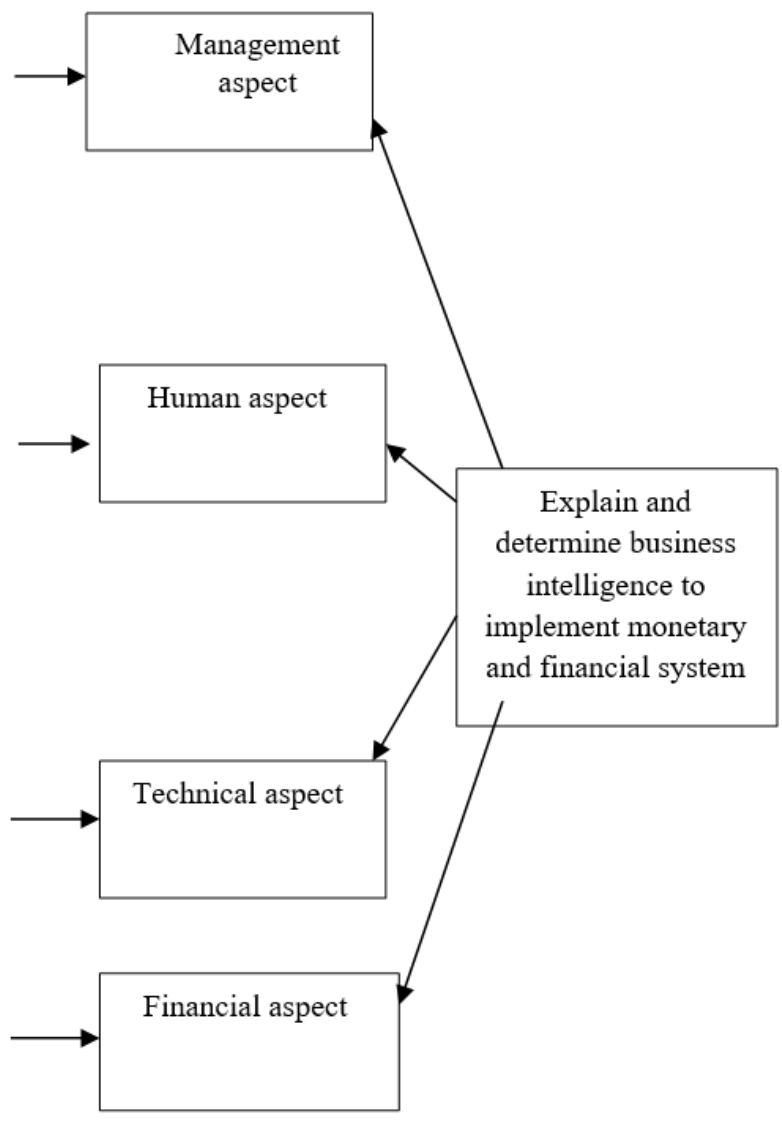




\section{The main hypothesis of the research}

- The business intelligence system in Asgarieh financial and credit institution in Rasht has desirable level to implement.

\section{Sub-hypotheses of the research}

- There is a significant relationship between the technical aspect and implementation of business intelligence system.

- There is a significant relationship between the management aspect and implementation of business intelligence system.

- There is a significant relationship between the human aspect and implementation of business intelligence system.

- There is a significant relationship between the financial aspect and implementation of business intelligence system.

\section{METHODOLOGY}

In general, research methods in the behavioral sciences can be divided in to two criteria: (a) the purpose of research and (b) data collection. This study, in term of purpose, is an applied research because the aim of applied research is the development of practical knowledge in specific underlying or in other words, directed toward practical application of knowledge. In terms of data collection, this study is described. Descriptive study aimed to describing the procedures set conditions or studied phenomena, and since the researcher is used field research and distribution and other characteristics of sample and survey method.

\section{Statistical Population}

The Statistical population consists of a group of people or objects in joint research activities and communicates with the object and subject. The population in this study is 160 managers and employees of Asgarieh financial and credit institution.

Sample size: Based on the sample size and taking into account the following formula to determine the sample size in this study for employees of Asgarieh financial institutions and credit in Rasht is 113 people in which 120 questionnaires were distributed among the employees and 115 questionnaires collected from them. Based on the sample size and taking into account the following formula to determine the sample size in this study for employees of Asgarieh financial institutions and credit in Rasht is 113 people in which 120 questionnaires were distributed among the employees and 115 questionnaires collected from them.

$$
n=\frac{\frac{z^{2} p q}{d^{2}}}{1+\frac{1}{N}\left(\frac{z^{2} p q}{d^{2}}-1\right)}
$$

$$
n=\frac{\frac{(1.96 * 1.96) * 0.5 *(1-0.5)}{0.05 * 0.05}}{1+\frac{1}{160}\left(\frac{(1.96 * 1.96) * 0.5 *(1-0.5)}{0.05 * 0.05}\right)}=113
$$

Sample size was determined by Cochran

Thus, according to the value of the 113 employees of the Asgarieh financial and credit institution as the sample size for this study was selected. The sampling method is random sampling.

Sampling method: In this study random sampling was used for sampling of the statistical population

Data collection method: In this study, methods of data collection are the library and field. In library studies, librarian resources and the Internet is used in the field of questionnaire method to collect information.

Data analysis: In this study, to analyze the data, descriptive and inferential statistical techniques were used. The software was used are as follow: SPSS19, Lisrel.

\section{RESULTS}

Time domain: Time domain of research is from April 2014 to August 2015 and time to send and receive the questionnaire is the period 16 to 31 July 2015.

Spatial domain: Spatial domain of the research is Asgarieh Financial and credit institution in of Rasht city in Guilan province. 


\section{Statistical Analysis of Survey Results}

\section{Part I: Descriptive Statistics}

- Investigate the respondents' level of education

Table 1. Distribution of respondents according to education

\begin{tabular}{ccc}
\hline Academic degree & Percentage & Frequency \\
\hline Diploma & 26.09 & 30 \\
\hline Associate Degree & 15.65 & 18 \\
\hline BS & 45.22 & 52 \\
\hline Senior & 10.43 & 12 \\
\hline Ph.D. & 2.61 & 3 \\
\hline Total & 100 & 115 \\
\hline
\end{tabular}

- Survey respondents job experience

Table 2. Frequency distribution of respondents according to job experience

\begin{tabular}{ccc}
\hline Job experience & Percentage & Frequency \\
\hline Under 5 years & 10.43 & 12 \\
\hline 10.5 years & 46.09 & 53 \\
\hline $20-10$ years & 30.43 & 35 \\
\hline 20 above & 13.05 & 15 \\
\hline Total & 100 & 115 \\
\hline
\end{tabular}

According to Table 3, amount of familiarity of the sample with intelligent systems, network and business intelligence is average.

Table 3. The rate of respondents' familiarity with smart systems, network and business intelligence

\begin{tabular}{ccc}
\hline Trading in & Percentage & Frequency \\
\hline very little & 0 & 0 \\
\hline Low & 13.04 & 15 \\
\hline Average & 63.48 & 73 \\
\hline Great & 16.65 & 18 \\
\hline too much & 7.83 & 9 \\
\hline Total & 100 & 115 \\
\hline
\end{tabular}

- Review the organizational position of respondents

Table 4. Frequency distribution of respondents according to organizational positions

\begin{tabular}{ccc}
\hline Job position & Frequency & Percentage \\
\hline Employee & 86 & 74.78 \\
\hline Expert & 14 & 12.17 \\
\hline Director & 5 & 4.35 \\
\hline Assistant & 10 & 8.7 \\
\hline Sum & 115 & 100 \\
\hline
\end{tabular}

The main hypothesis of this study: Business intelligence system status is desirable to implement in Asgarieh financial and credit institution. The main hypothesis of the study to assess the status of implementation of the organization's business intelligence system, so for the one-sample t-test was used to evaluate this hypothesis, which is completely described in the test: One-sample t-test to compare the way in which the average with a fixed number is the result of this test shows whether the corresponding average with fixed number has a significant difference or not? The questionnaire was prepared based on the Likert scale (five levels). In the questionnaire, we consider the average level of the system to implement business intelligence in organizations and examine whether level 3 status business intelligence system to implement in the lower or much higher than it, so level 3 represents consider the average one-sample t-test questionnaire to all.

Table 5. One-sample t-test to assess the status of implementation of business intelligence systems in the organization

\begin{tabular}{lcccc}
\hline Variable & $\begin{array}{c}\text { Number of } \\
\text { sample }\end{array}$ & $\begin{array}{c}\text { The value of } \\
\mathbf{T}\end{array}$ & $\begin{array}{c}\text { Freedom } \\
\text { degree }\end{array}$ & p-value \\
\hline The level of business intelligence system to implement in the organization & 115 & 18.827 & 114 & 0.000 \\
\hline
\end{tabular}


One-sample t-test to assess the status of implementation of business intelligence systems in accordance with Table 5 at a significance level of $1 \%$ and is significantly higher than 1.96. This means that the financial situation of Asgarieh credit and financial institution business intelligence system from the perspective of the respondents is much higher than average level.

Secondary hypotheses of the research: First sub-hypothesis: there is a significant relationship between the technical and business intelligence system implementation.

There is no significant relationship between technical and business intelligence system implementation.

HO: $\lambda=0$.

There is a significant relationship between technical and business intelligence system implementation.

$\mathrm{H} 1: \lambda \neq 0$

Table 6. Relations with the parameters in the model concepts

\begin{tabular}{lcccc}
\hline $\begin{array}{l}\text { Relations with the parameters in the model concepts } \\
\text { and business intelligence system implementation }\end{array}$ & The standard error & The value of $\mathbf{T}$ Significant level & Result \\
\hline
\end{tabular}

According to Table 6 , the results of model equations show that more than 99 certainty percent can be to say that technical aspect can measure the implementation of business intelligence systems $(\mathrm{P}<0.01 ; \mathrm{T}=6.85)$ as a result the hypothesis H0 rejected and H1 be approved.

The second sub-hypothesis: there is a significant relationship between the management and implementation of business intelligence systems,

There is no significant relationship between the management and implementation of business intelligence systems.

$\mathrm{H} 0: \lambda=0$

There is a significant relationship between the management and implementation of business intelligence systems.

$\mathrm{H} 1: \lambda \neq 0$

Table 7. Relations with the parameters in the model concepts

\begin{tabular}{lcccc}
\hline Relations with the parameters in the model concepts & The standard error & The value of $\mathbf{T}$ Significant level & Result \\
\hline $\begin{array}{l}\text { There is a significant relationship between the management } \\
\text { and implementation of business intelligence systems. }\end{array}$ & 0.068 & 8.32 & $\mathrm{P}<0.01$ & Index approved \\
\hline
\end{tabular}

According to Table 7, the results show that the equations model with more than 99 percent of certainty can be said management aspect can measure the implementation of business intelligence systems $(\mathrm{P}<0.0132 / 8 \mathrm{~T}=)$. As a result, the hypothesis H0 rejected and the hypothesis H1 is approved. The structural equation modeling, indexes that measure better than the other indexes, research variables, significant latent variable is assumed to be obvious and $\mathrm{T}$ values and standard errors were not calculated for it.

The third sub-hypothesis: there is a significant relationship between the human dimension and business intelligence system implementation.

There is no significant relationship between the human and business intelligence system implementation.

$\mathrm{H} 0: \lambda=0$

There is a significant relationship between the human and business intelligence system implementation.

$\mathrm{H} 1: \lambda \neq 0$

Table 8. Relations with the parameters in the model concepts

\begin{tabular}{lcccc}
\hline Relations with the parameters in the model concepts & The standard error & The value of $\mathbf{T}$ Significant level & Result \\
\hline $\begin{array}{l}\text { There is a significant relationship between the human } \\
\text { dimension and business intelligence system implementation }\end{array}$ & 0.45 & 7.26 & $\mathrm{P}<0.01$ & Index approved \\
\hline
\end{tabular}

According to Table 8, the results of model equations show that more than 99 percent of certainty can be said that human aspect can measure the implementation of business intelligence systems $(\mathrm{P}<0.01 ; \mathrm{T}=26 / 7)$ As a result hypothesis $\mathrm{H} 0$ rejected and hypothesis $\mathrm{H} 1$ approved.

The fourth sub-hypothesis: there is a significant relationship between the financial aspect and business intelligence system implementation.

There is no significant relationship between financial aspect and business intelligence system implementation.

$\mathrm{HO}: \lambda=0$

There is a significant relationship between the financial aspect and business intelligence system implementation. $\mathrm{H} 1: \lambda \neq 0$ 
Table 9. Relations with the parameters in the model concepts

\begin{tabular}{lcccc}
\hline Relations with the parameters in the model concepts & The standard error & The value of T Significant level & Result \\
\hline $\begin{array}{l}\text { There is a significant relationship between international } \\
\text { financial and business intelligence system implementation. }\end{array}$ & 0.096 & 8.95 & $\mathrm{P}<0.01$ & Index approved \\
\hline
\end{tabular}

According to Table 9, the results show that the model equations that can be said with more than 99 percent certainty that the financial aspect can measure the implementation of business intelligence systems $(\mathrm{P}<0.01$; $\mathrm{T}=95 / 8)$ As a result the hypothesis $\mathrm{H} 0$ rejected and hypothesis $\mathrm{H} 1$ be approved.

\section{DISCUSSION AND CONCLUSION}

\section{Recommendations According to the Results of Research Hypotheses}

The results of this study, which was conducted in Asgarieh financial and credit institution of Rasht, indicate that there is a possibility of implementing a business intelligence system in Asgarie financial and credit institution. In other words, the business intelligence system is desirable to implement in Asgarieh financial and credit institution. So for the successful implementation of business intelligence system implementation in the following offers suggested:

Suggestions with respect to the first sub-hypothesis: This study shows that there is a possibility of implementing a business intelligence system for technical aspect in Asgarieh financial and credit institution. In other words, the technical aspect can measure status of the business intelligence system for implementation.

Benefits of business intelligence solutions are more than anything requires appropriate and complete hardware and software infrastructure. There are systems including ERP, CRM, SCM integration with information systems and databases are compatible with each other or data repository can be useful and beneficial will greatly increase in the results of the implementation of this strategy. It is true that the hypothesis was approved, but has tried to attract more attention a technical dimension to business intelligence technology solution.

Suggestions with regard to the second sub-hypothesis: This study shows that there is a possibility to implement business intelligence solutions for the management of Asgarieh financial and credit institution. In other words, management aspect can measure the implementation of the organization's business intelligence system. So in order to successful implementation of business intelligence systems in organization, the following offers suggested:

(1) Senior managers must work with other managers of organization to reduce the amount of employee resistance against changes as much as possible.

(2) In the case of important researches such as business intelligence should be done extensive information in the organization and the employees and managers aware about the results of the use of this approach in the organization.

(3) Senior executives should encourage subordinate managers for cooperation in the implementation of the project.

Suggestions with regard to the third sub-hypothesis: This study shows that there is possibility to implement business intelligence systems of the human dimension in Asgarieh financial and credit institution. In other words, the human aspect can measure the implementation of business intelligence system status. So for the successful implementation of business intelligence system in organization, the following offers suggested:

(1) Increase the amount of cooperation in departments and units on projects related to IT

(2) Inform and educate personnel about the many benefits of business intelligence solutions in the organization

(3) The creation or management assistance based on the monitoring of IT projects and determine the duties in the organization

Suggestions with respect to the fourth sub-hypothesis: This study shows that there is a possibility to implement business intelligence systems for Asgarieh financial and credit institution. In other words, financial aspect can measure the status of implementation of the business intelligence system. In fact, financial aspect has a considerable influence on the success and failure of each project. The review of literature shows that over the coming years, investment will be increased in information technology and business intelligence companies and organizations. Therefore, can be improve and expand implementation of business intelligence solutions and increase funding for research and development and IT-related projects by allocating appropriate funding. 


\section{REFERENCES}

Amini, M. (2009). Studying the relationship between knowledge management systems and business intelligence decision support environments. Paper presented at the first International Conference on Software Engineering Iran. pp. 15-1.

Hosseini, F. (2004). The use of business intelligence as a strategic technology in Banking: Overview and detect fraud, a Master's thesis Tehran University (Qom Pardis university), Iran. 